\title{
Correction
}

\section{Erratum: Dash et al., Poly (ADP-Ribose) Polymerase-1 (PARP-1) Induction by Cocaine Is Post-Transcriptionally Regulated by miR-125b (eNeuro July/August 2017, 4(4) e0089-17.2017 1-16 https://doi.org/10.1523/ENEURO.0089-17.2017)}

In the article "Poly (ADP-Ribose) Polymerase-1 (PARP-1) Induction by Cocaine Is Post-Transcriptionally Regulated by miR-125b," by Sabyasachi Dash, Muthukumar Balasubramaniam, Tanu Rana, Arthur Godino, Emily G. Peck, Jeffery Shawn Goodwin, Fernando Villalta, Erin S. Calipari, Eric J. Nestler, Chandravanu Dash, and Jui Pandhare, which appeared as e0089-17.2017 in the July/August 2017 issue, the affiliations of authors Arthur Godino, Emily G. Peck, and Eric J. Nestler were cited incorrectly. Each is affiliated with the Fishberg Department of Neuroscience and Friedman Brain Institute, Icahn School of Medicine at Mount Sinai, New York, NY 10029. The article has been corrected accordingly. This correction does not affect the conclusions of the paper.

DOI:http://dx.doi.org/10.1523/ENEURO.0115-18.2018 